\title{
The hen model of human ovarian cancer develops anti-mesothelin autoantibodies in response to mesothelin expressing tumors
}

Yi Yu', Seby L Edassery ${ }^{1}$, Animesh Barua ${ }^{1,2,3}$, Jacques S Abramowicz ${ }^{2}$, Janice M Bahr ${ }^{4}$, Ingegerd Hellstrom ${ }^{5}$ and Judith L Luborsky ${ }^{1,2^{*}}$

\begin{abstract}
Objective: Study of the hen immune system led to seminal contributions to basic immunological principles. Recent studies of spontaneous ovarian cancer in the laying hen show strikingly similar tumor types and antigen expression compared to human ovarian cancer, suggesting hens would be valuable for studies of tumor immunology and pre-clinical vaccine development. Circulating mesothelin is a relatively specific marker for human ovarian cancer and autoantibodies to mesothelin were reported. We hypothesized that hen tumors express mesothelin and that circulating anti-mesothelin antibodies occur in response to tumors.

Methods: Mesothelin mRNA expression was analyzed by RT-PCR in hen ovarian tumors and normal ovaries. Mesothelin protein expression was evaluated by immunohistochemistry (IHC) and two-dimensional SDS-PAGE Western blots. Anti-mesothelin antibodies were assessed by immunoassay of sera from hens with normal ovaries and with ovarian tumors.

Results: Significant mesothelin mRNA expression was observed in 57\% (12/21) of hen ovarian tumors but not in normal ovaries and was found predominantly in serous tumors as in humans. Mesothelin protein was detected in tumors with mesothelin mRNA by $\mathrm{IHC}$ and 2D Western blots, but not in normal ovaries or tumors without mesothelin mRNA. Circulating anti-mesothelin antibodies occurred in $44 \%(n=4 / 9)$ of hens with ovarian tumors which express mesothelin mRNA and were not found in hens with tumors that did not express mesothelin $(n=0 / 5)$ or normal ovaries $(n=0 / 5)$.
\end{abstract}

Conclusion: The results support the utility of the hen as a novel model for preclinical studies of mesothelin as a biomarker and a target for immunotherapy.

Keywords: Mesothelin, Mesothelin antibodies, Ovarian Cancer, Hens, Animal Model

\section{Introduction}

Study of the hen immune system led to seminal contributions to basic immunological principles [1]. Recent studies of spontaneous ovarian cancer in the laying hen suggest it would be a valuable model for studies of ovarian tumor immunology. The laying hen spontaneously develops ovarian tumors with numerous similarities to human tumors [2-8]including similar tumor histology and tumor types [5]. The incidence of tumors increases

\footnotetext{
* Correspondence: Judith_Luborsky@rush.edu

'Department of Pharmacology, Rush University Medical Center, 1735 W Harrison Street, Chicago, IL 60612, USA

Full list of author information is available at the end of the article
}

with age as in human ovarian cancer and tumors are fully progressive and in late stages metastasize to distant sites $[2,9]$. Hen ovarian tumors show similar alterations in gene expression profiles compared to human tumors [4]. Moreover, multiple proteins are similarly expressed in hen and human ovarian tumors [10] and include CA125 [11], Selenium Binding Protein 1 [12], COX-1 [6,13], E-cadherin [14], VEGF [15,16] and CYP1B1 [17]. In addition, we showed that similar to human ovarian cancer [18] hens produce anti-ovarian and anti-tumor antibodies in response to ovarian tumors [19]. However, antigen specific responses are unexplored in the hen model.

\section{C) Biomed Central}


Mesothelin is a well characterized biomarker for ovarian cancer in human. Mesothelin is a $40 \mathrm{kDa}$ cell-surface differentiation antigen that is normally expressed at low levels and is restricted to tissues such as the mesothelial cells lining some body cavities and epithelial cells of kidney, tonsil, trachea, and fallopian tube [20,21]. However mesothelin is highly expressed in ovarian cancer, mesotheliomas and to a lesser extent in other cancers such as pancreatic, lung, and stomach [21]. Increased mesothelin protein expression was reported in $70 \%$ of ovarian epithelial tumors and up to $100 \%$ of serous papillary ovarian cancer [21-28]. Indeed, mesothelin is shed into the circulation [29] and is one of a few specific serum markers for ovarian cancer [30-32]. In addition, mesothelin autoantibodies were detected in the sera of patients whose tumors were positive for mesothelin in ovarian cancer [33]. The frequently elevated expression of mesothelin in cancer cells compared to normal cells and the immune response to mesothelin [32,34-37] have led to exploration of mesothelin as a therapeutic target for ovarian cancers $[26,31,38,39]$.

The biological function of mesothelin remains speculative. Studies of the mouse mesothelin gene show that it is not critical for development or reproduction in normal mice [40]. In ovarian cancer it is thought to have an effect on heterotypic cell-adhesion and cell-to-cell recognition and signaling by binding to another tumor antigen, CA125 (MUC16) to facilitate the cell invasiveness and metastasis [40-43].

Ovarian cancer has the highest mortality rate of the gynecological cancers. This is primarily due to a lack of symptoms and early detection tests. Therefore, the diagnosis of ovarian cancer primarily occurs at stage III/IV [44]. When ovarian cancer is detected early survival is greater than $80 \%[45,46]$, suggesting that earlier detection could significantly increase survival. The increased tissue expression and the presence of circulating mesothelin in human ovarian cancer is relatively specific and mesothelin shows promise as a specific marker and a target of immunotherapy for ovarian cancer. Efforts to understand the trajectory of biomarker expression and to validate early markers in pre-clinical studies are facilitated by the use of animal models. There are several models of ovarian cancer in rodents that were produced by genetic manipulation $[9,47-50]$. The observation that specific genetic alterations lead to specific histologic sub-types of ovarian tumors $[48,50]$ is informative and is congruent with the concept that the different sub-types rise by different mechanisms. However, few of these models develop spontaneous ovarian tumors with the hallmarks of human tumors.

In order to use the laying hen as a preclinical model to study spontaneous immunological responses to ovarian tumor antigens and to investigate the potential of mesothelin as a therapeutic target for cancer vaccine, our objective was to determine if the hen expresses mesothelin, if mesothelin expression is increased in ovarian tumors and if circulating mesothelin autoantibody is associated with ovarian tumors.

\section{Materials and methods \\ Animals}

White Leghorn laying hens ( $\mathrm{n}=31,2.5-3$ years old) were kept under a controlled light regimen (14 h light: $10 \mathrm{~h}$ dark) with food and water provided ad libitum at the Poultry Research Farm of the University of Illinois at Urbana-Champaign. Egg production and mortality records were maintained on a daily basis. Hens with normal ovarian morphology and histology had $\geq 5$ eggs per clutch, while those with ovarian tumors had $\leq 2$ eggs per clutch. Hens were euthanized according to an Institutional Animal Care and Use Committee (IACUC) approved protocol and the presence of tumors determined by gross morphology and histology. Sera and tissues were collected and processed for histology and mRNA and protein expression determination.

\section{Reverse Transcriptase-Polymerase Chain Reaction (RT- PCR) and mesothelin sequencing}

RNA was extracted with Trizol reagent (Invitrogen, Carlsbad, CA) as described previously [12]. The RNA concentration and quality were measured using 260/280 absorbance. Total RNA was treated with DNAse to remove genomic contamination and $1.0 \mu \mathrm{g}$ used for first strand synthesis using High Capacity cDNA Reverse transcription kit (Applied Biosystems Inc, Foster City, CA) following the suggested protocol. $25 \mathrm{ng}$ of first strand was used for each PCR reaction as template. Oligoperfect Designer software (Invitrogen; Carlsbad, CA) was used to design mesothelin (XM_414835.2) and actin (endogenous control, NM_205518.1). Gallus gallus primer sequences were shown in Table 1.

Amplicon 1 and 3 were used for sequencing and amplicon 2 was used to measure the mRNA expression and for PCR validation. PCR consisted of initial denaturation at $94^{\circ} \mathrm{C}$ for 3 minutes, followed by 35 cycles (each cycle at $94^{\circ} \mathrm{C}$ for $30 \mathrm{sec}, 57^{\circ} \mathrm{C}$ for $30 \mathrm{sec}$ and $72^{\circ} \mathrm{C}$ for 1 minute). PCR products were visualized by staining $3 \%$ agarose gels with ethidium bromide. The PCR product was purified (QIAquick PCR purification kit; Qiagen, Valencia, CA) and was then directly sequenced at the DNA sequencing faciilty at the University of Illinois at Chicago using the ABI BigDye Terminator in a ABI 3100 Genetic analyzer (Applied Biosystems Inc, Foster City, CA) using the same primers. Sequences from amplicon 1 and 3 and several other sequences from hen mesothelin cDNA clones available at NCBI, along with the predicted hen mRNA (XM_414835.2) were used for 
Table 1 RT-PCR primer pairs used for mesothelin and actin transcript amplification

\begin{tabular}{|c|c|c|}
\hline amplification target & primer sequence, $5^{\prime}-3^{\prime}$ & expected product size \\
\hline Amplicon1 & $\begin{array}{l}\text { For -GGCAAAGCTAGGGAGCTTG } \\
\text { Rev-AGGCCCAAACACAGTGTTG }\end{array}$ & 772 bp \\
\hline Amplicon2 & $\begin{array}{l}\text { For-ACCGCAGAGGATGTTAGCAA } \\
\text { Rev-TGTGAACAGGCTGAAGGATG }\end{array}$ & $251 \mathrm{bp}$ \\
\hline Amplicon3 & $\begin{array}{l}\text { For-GATGCTITAATGAGCCTGACG } \\
\text { Rev-GCTGAAACTTCGGCGTGAC }\end{array}$ & 202 bp \\
\hline actin & $\begin{array}{l}\text { For-GCCCTCTTCCAGCCATCTIT } \\
\text { Rev-TGGAGTTGAAGGTAGTTTCATGGAT }\end{array}$ & $67 \mathrm{bp}$ \\
\hline
\end{tabular}

in silico analysis to assemble the mesothelin mRNA sequence using the Blast and multiple alignment programs available at NCBI. The contour quantities (density of the band multiplied by the area of the band) of amplicon 2 bands in gels were measured using differential analysis module of Quantity One (BioRad, Hercules, CA). The contour quantities of actin bands were used for normalization of contour quantities of mesothelin bands.

\section{Two-dimensional SDS-Polyacrylamide Gel Electrophoresis (2D-SDS-PAGE) Western Blot}

Snap frozen ovarian tissues collected at euthanasia were stored at $-80^{\circ} \mathrm{C}$ until use. Tissues were pulverized in a dry ice-acetone bath and homogenized with a Polytron (Brinkman Instruments, Westbury, NY) in ice-cold Trissucrose buffer, $\mathrm{pH}$ 7.4, (40 mM HCl, 5 mM MgSO4, $0.25 \mathrm{M}$ sucrose) containing $1 \mu \mathrm{l} / 1 \mathrm{~mL}$ protease inhibitor cocktail (Sigma, St. Louis, MO). The homogenate was centrifuged $(1,000 \times \mathrm{g}, 10$ minutes $)$, the supernatant collected and protein was measured (Bradford protein assay kit; BioRad, Hercules, CA) with bovine serum albumin as a standard.

Three groups of ovarian tissues were selected based on the RT-PCR result, (a) ovarian tumors $(n=4)$ with mesothelin mRNA expression and (b) ovarian tumors $(\mathrm{n}=$ 4) and (c) normal ovaries $(n=4)$ without mesothelin mRNA expression. Tissue groups were pooled at equivalent protein concentration for 2D PAGE Western blot. $150 \mu \mathrm{g}$ of protein was passively rehydrated into immobilized pH gradient (IPG) strips (BioRad, 5-8 NL) and isoelectric focusing was done according to the manufacturers' protocol. The IPG strip was applied to a $10 \%$ Tris-HCL SDS-PAGE gel (Biorad, Hercules, CA) and electrophoresed. The proteins in the gel were transferred to nitrocellulose membranes using a semi-dry transfer apparatus (BioRad, Hercules, CA), and after blocking ( $1 \times$ blocking buffer [Sigma-Aldrich, St. Louis, MO] containing $0.05 \%$ Tween) ( 1 hour, $22^{\circ} \mathrm{C}$ ), the membranes were probed with mesothelin monoclonal antibody Clone 4H3 [32] (1:5000, 16 hours, $\left.4^{\circ} \mathrm{C}\right)$. After washing $(3 \times)$ with TBST (TBS containing $0.05 \%$ Tween), membranes were incubated with goat anti mouse IgG conjugated with horseradish peroxidase (Jackson ImmunoResearch Laboratories, Inc. West Grove, PA) as secondary antibody $\left(1: 10,000,1\right.$ hour, $\left.22^{\circ} \mathrm{C}\right)$. Antibody reaction was visualized with SuperSignal West dura extended duration chemiluminescence substrate (Thermo Scientific/Pierce, Rockford, IL) and images were captured with a Chemidoc imaging system (BioRad, Hercules, CA).

\section{Histology and Immunohistochemistry}

As described previously[5], tissue fixed in 10\% buffered formalin and paraffin-embedded was sectioned (5 um), and mounted on microscope slides. Deparaffinized sections were boiled in antigen unmasking solution (11 minutes, 1:100; Vector Laboratories, Burlingame, CA) and incubated in $0.3 \%$ hydrogen peroxide-methanol (20 minutes, $22^{\circ} \mathrm{C}$ ) to block endogenous peroxidase activity. Sections were rinsed in phosphate buffered saline (PBS), blocked $\left(2.5 \%\right.$ normal horse serum; 20 minutes, $\left.22^{\circ} \mathrm{C}\right)$ and incubated $\left(2\right.$ hours, $\left.22^{\circ} \mathrm{C}\right)$ with a monoclonal antibody to human mesothelin (1:200; clone $4 \mathrm{H} 3$ [32] diluted in PBS containing 1\% BSA). Sections were washed in PBS and incubated $\left(1\right.$ hour, $\left.22^{\circ} \mathrm{C}\right)$ with a secondary antibody that is species independent (universal biotinylated anti-immunoglobulin, Vector Laboratories, Burlingame, CA) followed by $\left(1\right.$ hour, $\left.22^{\circ} \mathrm{C}\right)$ Avidinhorseradish peroxidase (HRP) Complex reagent according to manufacturer's instruction (Vector Laboratories, Burlingame, CA). Control staining consisted of replacing the primary antibody with PBS containing 1\% BSA. The HRP was reacted with diaminobenzidine substrate (R.T. U. Vectastain Kit, Vector Laboratories, Burlingame, CA) and counterstained with Hematoxylin. Images were acquired using an Olympus Biological Microscope BX41 (Olympus, Tokyo, Japan) with a camera adaptor UCMAD3 and were analyzed using Soft Imaging System, MicroSuite $^{\mathrm{TM}}$ Biological Suite software.

\section{Mesothelin Antibody Immunoassay}

Three groups of hen sera were tested for antibodies to human mesothelin based on RT-PCR result using the assay described by Hellstrom et al. [35]: (group 1) hens with mesothelin positive ovarian tumors $(n=9)$, (group 2 ) hens with mesothelin negative ovarian tumors $(n=5)$, 
and (group 3) normal hens $(\mathrm{n}=5)$. ELISA plates were coated (100 ul of $5 \mathrm{ug} / \mathrm{mL}$ of purified mesothelin diluted in carbonate bicarbonate buffer) and incubated overnight. The plates were blocked ( $3 \%$ bovine serum albumin (BSA); 2 hours) and washed with PBS containing $0.1 \%$ Tween 20. Sera were serially diluted from 1:100 to 1:200 with PBS containing 3\% BSA and added to each well (1 hour, $22^{\circ} \mathrm{C}$ ); $3 \%$ BSA was used as a negative control. Mouse anti chicken IgY conjugated with horseradish peroxidase was added as the secondary antibody $(1: 1000$, 1 hour, $22^{\circ} \mathrm{C}$ ). The plates were washed with PBS containing $0.1 \%$ Tween 20 and sureBlue TMB Microwell Peroxidase substrate was added (15 minutes). The reaction was stopped using TMB stop solution. Results were determined as optical density (OD) at $450 \mathrm{~nm}$.

\section{Statistical analysis}

A Fishers exact test was used to determine if difference between groups were significant for mesothelin mRNA expression. The difference in mean values of the optical density for each group in the mesothelin antibody immunoassay was assessed with a t test using Welch's correction.

\section{Results}

In silico analysis of mesothelin transcripts

The hen genome was released in 2004. The NCBI database contains several sequence fragments for the mesothelin gene as well as a predicted mRNA sequence for mesothelin (XM_414835.2). In order to confirm that the predicted hen mesothelin mRNA sequence (sequence 1 in Figure 1) is expressed in the hen ovary, we aligned the mesothelin mRNA sequence using several sequences from cDNA clones available at NCBI Genbank: DR426891, BU237188, BU421473, BU456162, DR429030 and DN851245 (sequences 2 to 7, Figure 1) using the NCBI multiple alignment program. The resulting contig had two gaps; one gap occurred between the predicted mesothelin mRNA nucleotide positions 703 to 1233 and another short gap of 7 nucleotides occurred between positions 2357 to 2364 . We designed two primer pairs to amplify PCR products to fill these two gaps and the sequences which form amplicon 1 and 3 (sequence 8 and 10 in Figure 1) were aligned perfectly with the contig we obtained previously. These results clearly showed that the predicted mesothelin mRNA sequences are expressed in chicken ovary.

\section{Expression of mesothelin in normal ovary and ovarian tumors}

The mesothelin primer pair 2 was designed to produce a $251 \mathrm{bp}$ product between exon 8 and exon 10. It was detected in $57 \%(12 / 21)$ of ovarian cancers (Figure $2 \mathrm{~A})$, including $75 \%$ (3/4) of serous, $33 \%$ (2/6) of mucinous, $25 \%$ $(1 / 4)$ of endometrioid and $86 \%(6 / 7)$ of mixed histology tumors. In normal ovaries $(\mathrm{n}=10)$, no mesothelin mRNA was detected in agarose gels $(n=10)$ (Figure $2 A)$. The difference in mesothelin mRNA expression between normal and tumor containing ovaries estimated from normalized contour quantities of bands (Figure 2B) was significant ( $\mathrm{p}<0.0001$, Fishers exact test). The 251 bp product was purified, sequenced and blasted against hen genome. The blast result confirmed that the sequence is from hen mesothelin mRNA.

Two-dimensional -SDS-PAGE Western blots of pooled mesothelin mRNA positive ovarian tumors $(n=4)$ showed two predominant isoelectric trails of immunoreactive proteins around $80 \mathrm{kDa}$ and $40 \mathrm{kDa}$ (Figure 3, left). The pI range of these trails was 5.6 to 6.6 , consistent with the predicted $\mathrm{pI}$ of 6.6. We also observed faint reactions around $30 \mathrm{kD}$ in pooled tumor ovaries. No detectable level of immunoreactive protein was found in the pooled mesothelin mRNA negative tumors (Figure 3, middle) or in the pooled normal ovarian tissues (Figure 3, right).

\section{Localization of mesothelin in normal ovary and ovarian tumors}

Mesothelin expression was examined by immunohistochemistry in normal ovary $(\mathrm{n}=4)$ and selected ovaries

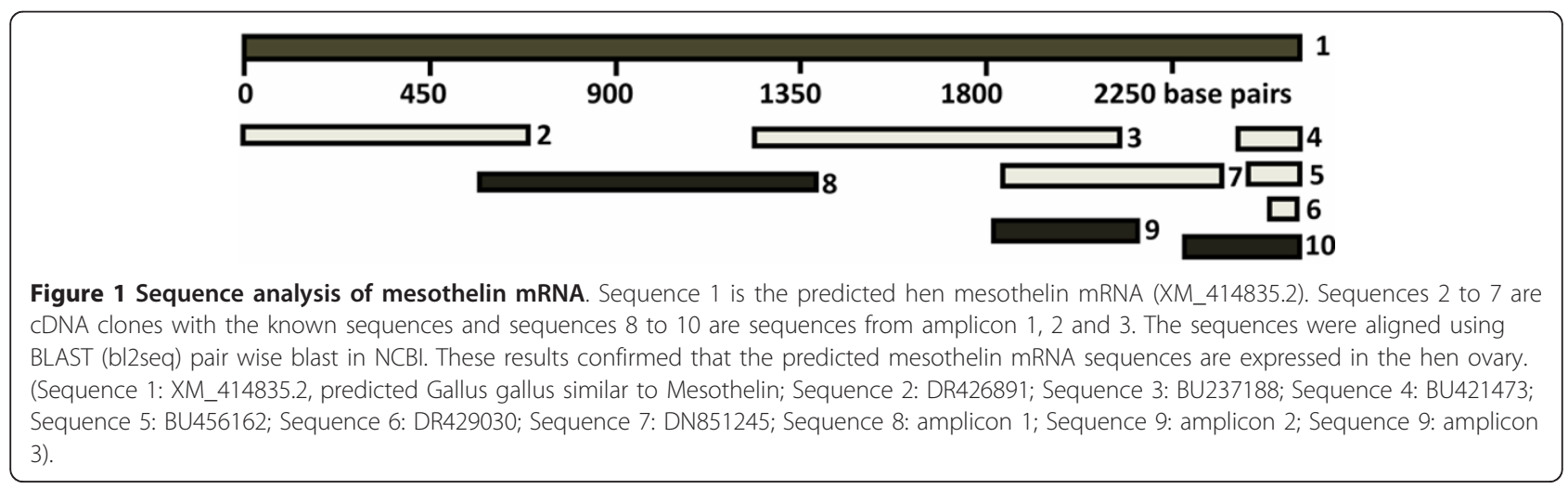




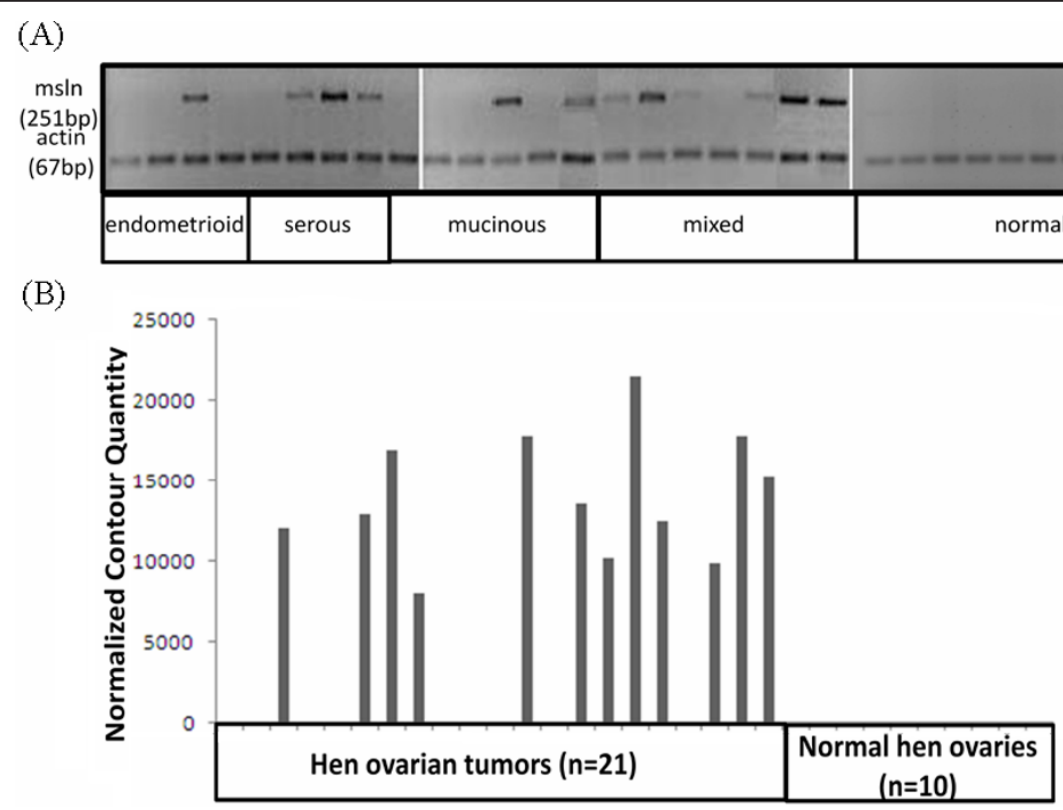

Figure 2 Examples of mesothelin mRNA expression in hen ovaries containing tumors and in normal ovaries. (A) mRNA was detected with hen specific primer based on the predicted hen mesothelin sequence. Mesothelin mRNA expression was identified in 1/4 (25\%) endometrioid tumors, 3/4 (75\%) serous carcinomas, 2/6 (33\%) mucinous carcinomas, and 6/7 (86\%) mixed histology tumors. Mesothelin was not detected in normal ovaries. (B) Measurement of mesothelin mRNA expression using differential density analysis with the loading control $\beta$-actin used as a reference. Samples are in the same order in A and B.

containing tumors $(n=6)$. No specific staining was seen in the normal ovary (Figure $4 \mathrm{~A}$ and $4 \mathrm{~B}$ ) or in sections from ovarian tumors that did not show mesothelin mRNA expression (Figure 4D). However, in a very few areas, there was some weak staining in the epithelial cells and stroma of normal ovary (Figure 4C) and ovarian tumors that did not show mesothelin mRNA expression (Figure $4 \mathrm{E}$ and $4 \mathrm{~F}$ ). In contrast, in the tumor ovaries that exhibited mesothelin mRNA expression, intense staining was seen in surface epithelial cells, in the ovarian stroma (Figure 4G) and in aggregates of tumor cells (Figure 4I). The result showed that mesothelin expression is in small clusters of cells and appears to be at the surface of single cells (Figure $4 \mathrm{H}$ ).

\section{Detection of circulating autoantibody to mesothelin}

At serum dilutions of 1:100 and 1:200, 44\% (4/9) of hens with mesothelin mRNA positive tumors, but none that did not express mesothelin (tumors or normal ovaries), had OD values greater than the cutoff value for that dilution (mean of normal serum plus two standard deviation). If the tumor type is considered in the hens with circulating mesothelin antibody, three out of the four $(75 \%)$ were serous carcinomas (Figure 5$)$. The

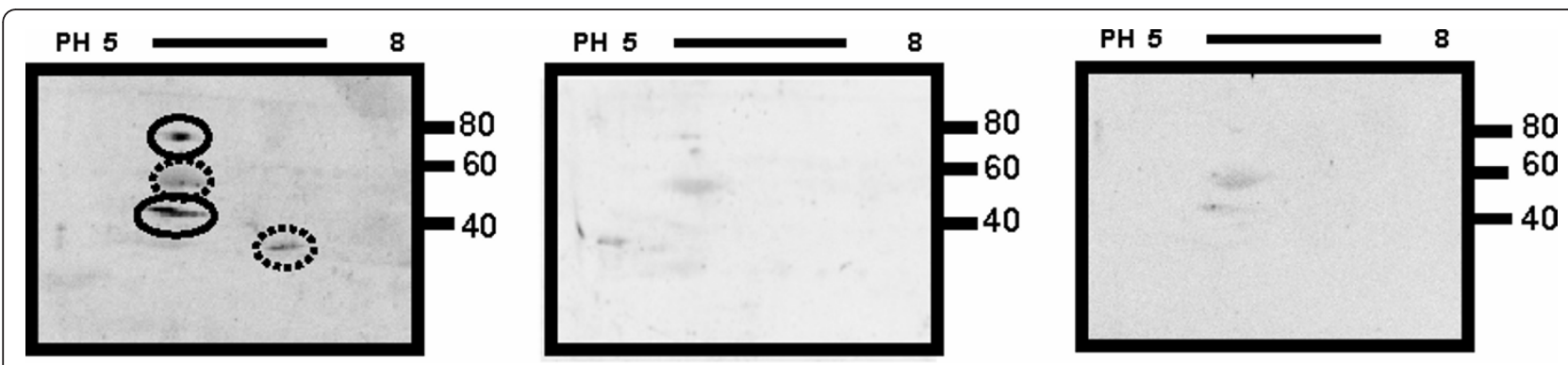

Figure 3 Comparison of the expression of mesothelin protein in mRNA positive tumor ovaries (left), mRNA negative tumor ovaries (middle) and in normal ovaries (right). Mesothelin was detected at a pl range of 5.6 to 6.6 and molecular weights of 80 and $40 \mathrm{kDa}$ (solid circles) in 2D Western blots using a monoclonal antibody to human mesothelin (clone 4H3). No mesothelin was detected in mRNA negative tumor ovaries or in normal ovaries. Some faint reactions (dotted circle) were observed in mRNA positive tumor ovaries blot and the identity of those spots remains to be determined. 


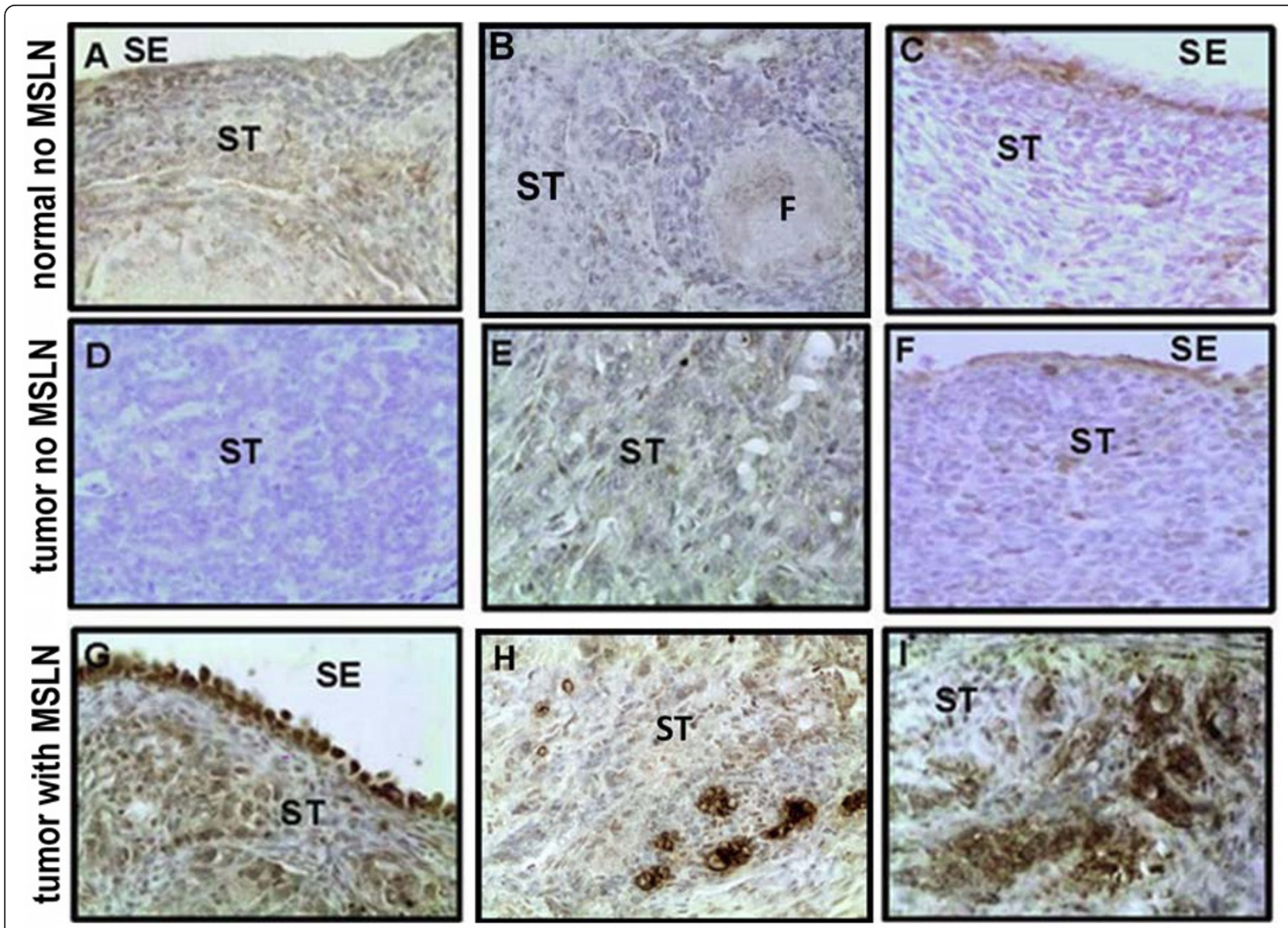

Figure 4 Immunohistochemical localization of mesothelin in normal hen ovaries and hen ovaries containing tumor. Staining was not observed in normal ovaries (A-C) in either the stromal or follicular (F) compartments or in ovarian tumors that did not express mesothelin (D-F). Mesothelin staining was observed in the ovarian surface epithelium (SE) and clusters of cells in the ovarian stroma (ST) of tumors that express mesothelin (G-I). Examples of different ovarian tumor histology are shown ( $D$ and $F$, advanced mucinous tumor; $E$, advanced endometrioid tumor; $\mathrm{G}$ and $\mathrm{H}$, advanced serous and endometrioid mixed tumor respectively; l, advanced serous tumor). The original magnification was 40x.

mesothelin antibody levels in hens with mesothelin mRNA positive tumors is significantly higher than in hens with negative tumors at a serum dilution of 1:100 ( $\mathrm{p}=0.039$, one-tailed $\mathrm{t}$ test with Welch's correction) and 1:200 $(\mathrm{p}=0.030$, one-tailed t test with Welch's correction).

\section{Discussion}

The results demonstrate for the first time that, similar to human ovarian tumors, mesothelin mRNA and protein are expressed in hen ovarian tumors and not in normal ovaries. This is also the first report of an antigen specific immune response in hens with tumors, and similar to humans serum mesothelin autoantibodies only occur in response to ovarian tumors that express mesothelin.

Mesothelin expression in human cancers has been studied extensively [21-28]. Previous studies showed that mesothelin protein frequently is expressed in human ovarian carcinomas and although there are some differences among studies, mesothelin is predominantly expressed in serous tumors [21,22], similar to the findings of this study. In our study using a chicken specific primer for RT-PCR analysis showed that mesothelin mRNA was increased significantly in hen ovarian tumors compared to normal ovaries. Similar to the human expression pattern, $75 \%$ of the hen serous ovarian tumors had mesothelin gene expression, other subtypes had varying degrees of expression but to a lesser extent than serous carcinoma and none of the normal ovaries had detectable levels of mesothelin mRNA.

Protein expression determined by Western blot analysis and immunohistochemistry was consistent with the mRNA results; mesothelin protein was expressed in tumors with mesothelin mRNA and was absent in normal ovaries. The predicted hen mesothelin sequence has 

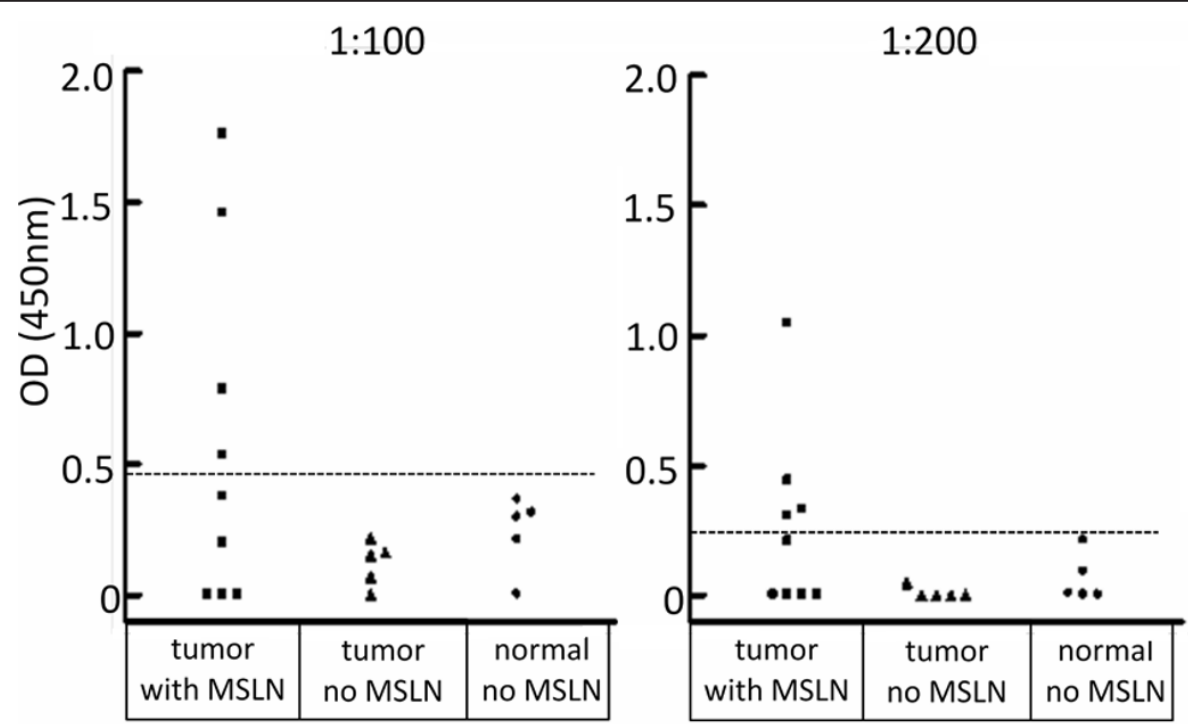

Figure 5 Circulating autoantibodies to mesothelin were detected in sera of hens with mesothelin mRNA expressing ovarian tumors by immunoassay. Sera were tested at dilutions of 1:100 and 1:200. Four of the nine hen sera with mesothelin PCR positive ovarian tumor are positive at both dilutions. None of the sera from hens without mesothelin mRNA expression had an optical density (OD) above the cutoff value for mesothelin antibody. The cutoff was determined as the mean value of normal controls plus two standard deviations above the mean. The cutoff value for positive reactions was 0.49 at 1:100 and 0.23 at 1:200.

797 amino acids, a pI of 6.6 and a molecular weight of $88 \mathrm{kDa}$. Consistent with the estimated molecular size of hen mesothelin we observed two predominant trails of protein 2D Western blots; the one slightly above $80 \mathrm{kDa}$ could be the full length predicted hen mesothelin, while the one around $40 \mathrm{kDa}$ could be due to alternate splice variants $[28,51]$. By immunohistochemistry using the same anti-human mesothelin antibody as for Western blot analysis, we observed patterns of mesothelin expression that were consistent with the mRNA and protein expression. Similar to observations in human ovarian tumors $[22,26,52,53]$, there was limited background stain in normal hen ovary and tumors that did not have mesothelin mRNA expression while there was intense staining of surface epithelial cells, tumor cells and clusters of cells in the ovarian stroma of mesothelin mRNA expressing tumors; cell surface staining was more intense than in the cytoplasm.

In addition to elevated expression of mesothelin in ovarian tumors, there was evidence of circulating mesothelin antibodies in hens with ovarian tumors. This corresponds to the reports of Hellstrom et al. [35] and Ho et al. [33] of mesothelin antibodies in humans and is also consistent with our previous report of anti-ovarian antibodies in the hen and humans with ovarian tumors [19]. It should be noted that we used human mesothelin as an immunoassay antigen since there currently are no reagents for a chicken specific anti-mesothelin immunoassay. The presence of a humoral immune reaction to ovarian tumors in the hen suggests it will be possible to use the hen for pre-clinical studies of anti-mesothelin vaccines.

In summary, the laying hen is a novel animal model of ovarian cancer because it spontaneous develops ovarian tumors with a striking histological resemblance to human ovarian tumors. The results of this study add to the growing list of ovarian cancer biomarkers that have been shown to be expressed both in hen and human. Our findings show that mesothelin gene and protein expression are elevated in chicken ovarian tumors and the results further validate the laying hen as an animal model for human ovarian cancer.

\section{Acknowledgements}

This work is supported by R01Al 055060 (JL), NIH R01CA134487 (IH \& JL), DOD OC073325 (JL), Ovarian Cancer SPORE (P50CA83636) Development Award (JL) and Young Investigator Award (AB), Prevent Cancer Foundation $(A B)$, the Joy Piccolo O'Connell/Gavers Women's Cancer Award (JL), Segal Women's Cancer Research Fund (AB) and a University Committee on Research Grant (AB).

\section{Author details}

'Department of Pharmacology, Rush University Medical Center, 1735 W Harrison Street, Chicago, IL 60612, USA. ${ }^{2}$ Department of Obstetrics and Gynecology, Rush University Medical Center, 1725 W Harrison Street, Chicago, IL 60612, USA. ${ }^{3}$ Department of Pathology, Rush University Medical Center, 1750 W Harrison Street, Chicago, IL 60612, USA. ${ }^{4}$ Department of Animal Sciences, University of Illinois, Urbana-Champagne, 1207 W. Gregory Drive, Urbana, IL 61801, USA. ${ }^{5}$ Department of Pathology, University of Washington, 300 9th Ave Haborview R\&T Rm 710, Seattle, WA 98104, USA.

\section{Authors' contributions}

YY performed a majority of the experiments and wrote the manuscript. 
SE supervised experiments as needed, designed the PCR primer and assisted with hen mesothelin sequencing.

$A B$ harvested the hen tissues and assisted with the immunohistochemistry. JA supervised the ultrasound and assisted with hen selection and tissue harvesting.

JB assisted with hen selection and contributed expertise in hen physiology; hens are maintained under her supervision.

$\mathrm{IH}$ performed the anti-mesothelin antibody tests, provided human purified and recombinant mesothelin and contributed to the manuscript. $J$ developed the concept for the study with $Y Y$, assisted with the experimental design, data interpretation and manuscript preparation and revisions.

All authors read and approved the final manuscript.

\section{Conflict of Interest statement}

The authors declare that they have no competing interests.

Received: 31 May 2011 Accepted: 29 July 2011 Published: 29 July 2011

\section{References}

1. Davison TF: The immunologists' debt to the chicken. Br Poult Sci 2003, 44:6-21.

2. Fredrickson TN: Ovarian tumors of the hen. Environ Health Perspect 1987, 73:35-51.

3. Urick ME, Giles JR, Johnson PA: Dietary aspirin decreases the stage of ovarian cancer in the hen. Gynecol Oncol 2009, 112:166-170.

4. Hakim AA, Barry CP, Barnes HJ, Anderson KE, Petitte J, Whitaker R, Lancaster JM, Wenham RM, Carver DK, Turbov J, et al: Ovarian adenocarcinomas in the laying hen and women share similar alterations in p53, ras, and HER-2/neu. Cancer Prev Res (Phila) 2009, 2:114-121.

5. Barua A, Bitterman P, Abramowicz JS, Dirks AL, Bahr JM, Hales DB, Bradaric MJ, Edassery SL, Rotmensch J, Luborsky JL: Histopathology of ovarian tumors in laying hens: a preclinical model of human ovarian cancer. Int J Gynecol Cancer 2009, 19:531-539.

6. Hales DB, Zhuge Y, Lagman JA, Ansenberger K, Mahon C, Barua A, Luborsky JL, Bahr JM: Cyclooxygenases expression and distribution in the normal ovary and their role in ovarian cancer in the domestic hen (Gallus domesticus). Endocrine 2008, 33:235-244.

7. Hawkridge AM, Wysocky RB, Petitte JN, Anderson KE, Mozdziak PE, Fletcher OJ, Horowitz JM, Muddiman DC: Measuring the intra-individual variability of the plasma proteome in the chicken model of spontaneous ovarian adenocarcinoma. Anal Bioanal Chem 398, 737-749.

8. Gonzalez Bosquet J, Peedicayil A, Maguire J, Chien J, Rodriguez GC, Whitaker R, Petitte JN, Anderson KE, Barnes HJ, Shridhar V, Cliby WA Comparison of gene expression patterns between avian and human ovarian cancers. Gynecol Oncol 120:256-264.

9. Vanderhyden BC, Shaw TJ, Ethier JF: Animal models of ovarian cancer. Reprod Biol Endocrinol 2003, 1:67.

10. Rodriguez-Burford C, Barnes MN, Berry W, Partridge EE, Grizzle WE: Immunohistochemical expression of molecular markers in an avian model: a potential model for preclinical evaluation of agents for ovarian cancer chemoprevention. Gynecol Oncol 2001, 81:373-379.

11. Jackson E, Anderson K, Ashwell C, Petitte J, Mozdziak PE: CA125 expression in spontaneous ovarian adenocarcinomas from laying hens. Gynecol Oncol 2007, 104:192-198.

12. Stammer K, Edassery SL, Barua A, Bitterman P, Bahr JM, Hales DB, Luborsky JL: Selenium-Binding Protein 1 expression in ovaries and ovarian tumors in the laying hen, a spontaneous model of human ovarian cancer. Gynecol Oncol 2008, 109:115-121.

13. Urick ME, Johnson PA: Cyclooxygenase 1 and 2 mRNA and protein expression in the Gallus domesticus model of ovarian cancer. Gynecol Oncol 2006, 103:673-678.

14. Ansenberger K, Zhuge Y, Lagman JA, Richards C, Barua A, Bahr JM, Hales DB: E-cadherin expression in ovarian cancer in the laying hen, Gallus domesticus, compared to human ovarian cancer. Gynecol Oncol 2009, 113:362-369.

15. Urick ME, Giles JR, Johnson PA: VEGF expression and the effect of NSAIDs on ascites cell proliferation in the hen model of ovarian cancer. Gynecol Oncol 2008, 110:418-424.

16. Barua A, Bitterman P, Bahr JM, Bradaric MJ, Hales DB, Luborsky JL, Abramowicz JS: Detection of tumor-associated neoangiogenesis by
Doppler ultrasonography during early-stage ovarian cancer in laying hens: a preclinical model of human spontaneous ovarian cancer. $J$ Ultrasound Med 29:173-182.

17. Zhuge $Y$, Lagman JA, Ansenberger K, Mahon CJ, Daikoku T, Dey SK, Bahr JM, Hales DB: CYP1B1 expression in ovarian cancer in the laying hen Gallusdomesticus. Gynecol Oncol 2009, 112:171-178.

18. Barua A, Bradaric MJ, Kebede T, Espinosa S, Edassery SL, Bitterman P Rotmensch J, Luborsky JL: Anti-ovarian and anti-tumor antibodies in women with ovarian cancer. Am J Reprod Immunol 2007, 57:243-249.

19. Barua A, Edassery SL, Bitterman P, Abramowicz JS, Dirks AL, Bahr JM, Hales DB, Bradaric MJ, Luborsky JL: Prevalence of antitumor antibodies in laying hen model of human ovarian cancer. Int J Gynecol Cancer 2009, 19:500-507.

20. Chang K, Pastan I: Molecular cloning of mesothelin, a differentiation antigen present on mesothelium, mesotheliomas, and ovarian cancers. Proc Natl Acad Sci USA 1996, 93:136-140.

21. Frierson HF, Moskaluk CA, Powell SM, Zhang H, Cerilli LA, Stoler MH, Cathro H, Hampton GM: Large-scale molecular and tissue microarray analysis of mesothelin expression in common human carcinomas. Hum Pathol 2003, 34:605-609.

22. Ordonez NG: Application of mesothelin immunostaining in tumor diagnosis. Am J Surg Pathol 2003, 27:1418-1428.

23. Chang K, Pastan I: Molecular cloning and expression of a CDNA encoding a protein detected by the $\mathrm{K} 1$ antibody from an ovarian carcinoma (OVCAR-3) cell line. Int J Cancer 1994, 57:90-97.

24. Hough CD, Sherman-Baust CA, Pizer ES, Montz FJ, Im DD, Rosenshein NB, Cho KR, Riggins GJ, Morin PJ: Large-scale serial analysis of gene expression reveals genes differentially expressed in ovarian cancer. Cancer Res 2000, 60:6281-6287.

25. Argani P, lacobuzio-Donahue C, Ryu B, Rosty C, Goggins M, Wilentz RE, Murugesan SR, Leach SD, Jaffee $E_{1}$ Yeo CJ, et al: Mesothelin is overexpressed in the vast majority of ductal adenocarcinomas of the pancreas: identification of a new pancreatic cancer marker by serial analysis of gene expression (SAGE). Clin Cancer Res 2001, 7:3862-3868.

26. Hassan R, Ho M: Mesothelin targeted cancer immunotherapy. Eur J Cancer 2008, 44:46-53

27. Obulhasim G, Fujii H, Matsumoto T, Yasen M, Abe M, Matsuoka S, Ohtsuji N, Hino O: Mesothelin gene expression and promoter methylation/ hypomethylation in gynecological tumors. Eur J Gynaecol Oncol 2010, 31:63-71.

28. Muminova ZE, Strong TV, Shaw DR: Characterization of human mesothelin transcripts in ovarian and pancreatic cancer. BMC Cancer 2004, 4:19.

29. Zhang Y, Pastan I: High shed antigen levels within tumors: an additional barrier to immunoconjugate therapy. Clin Cancer Res 2008, 14:7981-7986.

30. Rosen DG, Wang L, Atkinson JN, Yu Y, Lu KH, Diamandis EP, Hellstrom I, Mok SC, Liu J, Bast RC Jr: Potential markers that complement expression of CA125 in epithelial ovarian cancer. Gynecol Oncol 2005, 99:267-277.

31. Hassan R, Bera T, Pastan I: Mesothelin: a new target for immunotherapy. Clin Cancer Res 2004, 10:3937-3942.

32. Hellstrom I, Raycraft J, Kanan S, Sardesai NY, Verch T, Yang Y, Hellstrom KE: Mesothelin variant 1 is released from tumor cells as a diagnostic marker. Cancer Epidemiol Biomarkers Prev 2006, 15:1014-1020.

33. Ho M, Hassan R, Zhang J, Wang QC, Onda M, Bera T, Pastan I: Humoral immune response to mesothelin in mesothelioma and ovarian cancer patients. Clin Cancer Res 2005, 11:3814-3820

34. Hassan R, Remaley AT, Sampson ML, Zhang J, Cox DD, Pingpank J, Alexander R, Willingham M, Pastan I, Onda M: Detection and quantitation of serum mesothelin, a tumor marker for patients with mesothelioma and ovarian cancer. Clin Cancer Res 2006, 12:447-453.

35. Hellstrom I, Friedman E, Verch T, Yang Y, Korach J, Jaffar J, Swisher E, Zhang B, Ben-Baruch G, Tan MC, et al: Anti-mesothelin antibodies and circulating mesothelin relate to the clinical state in ovarian cancer patients. Cancer Epidemiol Biomarkers Prev 2008, 17:1520-1526.

36. Mclntosh MW, Drescher C, Karlan B, Scholler N, Urban N, Hellstrom KE, Hellstrom I: Combining CA 125 and SMR serum markers for diagnosis and early detection of ovarian carcinoma. Gynecol Oncol 2004, 95:9-15.

37. Huang CY, Cheng WF, Lee CN, Su YN, Chien SC, Tzeng YL, Hsieh CY, Chen CA: Serum mesothelin in epithelial ovarian carcinoma: a new screening marker and prognostic factor. Anticancer Res 2006, 26:4721-4728. 
38. Chang CL, Wu TC, Hung CF: Control of human mesothelin-expressing tumors by DNA vaccines. Gene Ther 2007, 14:1189-1198.

39. Hellstrom KE, Hellstrom I: Vaccines to treat cancer-an old approach whose time has arrived. J Cell Biochem 2007, 102:291-300.

40. Bera TK, Pastan I: Mesothelin is not required for normal mouse development or reproduction. Mol Cell Biol 2000, 20:2902-2906.

41. Scholler N, Garvik B, Hayden-Ledbetter M, Kline T, Urban N: Development of a CA125-mesothelin cell adhesion assay as a screening tool for biologics discovery. Cancer Lett 2007, 247:130-136.

42. Rump A, Morikawa Y, Tanaka M, Minami S, Umesaki N, Takeuchi M, Miyajima A: Binding of ovarian cancer antigen CA125/MUC16 to mesothelin mediates cell adhesion. J Biol Chem 2004, 279:9190-9198.

43. Gubbels JA, Belisle J, Onda M, Rancourt C, Migneault M, Ho M, Bera TK, Connor J, Sathyanarayana BK, Lee B, et al: Mesothelin-MUC16 binding is a high affinity, $\mathrm{N}$-glycan dependent interaction that facilitates peritoneal metastasis of ovarian tumors. Mol Cancer 2006, 5:50.

44. McLemore MR, Aouizerat B: Introducing the MUC16 gene: implications for prevention and early detection in epithelial ovarian cancer. Biol Res Nurs 2005, 6:262-267.

45. Goodman MT, Howe HL: Descriptive epidemiology of ovarian cancer in the United States, 1992-1997. Cancer 2003, 97:2615-2630.

46. Goodman MT, Correa CN, Tung KH, Roffers SD, Cheng Wu X, Young JL, Wilkens LR, Carney ME, Howe HL: Stage at diagnosis of ovarian cancer in the United States, 1992-1997. Cancer 2003, 97:2648-2659.

47. Lu KH, Yates MS, Mok SC: The monkey, the hen, and the mouse: models to advance ovarian cancer chemoprevention. Cancer Prev Res (Phila) 2009, 2:773-775

48. Liu J, Yang G, Thompson-Lanza JA, Glassman A, Hayes K, Patterson A, Marquez RT, Auersperg N, Yu Y, Hahn WC, et al: A genetically defined model for human ovarian cancer. Cancer Res 2004, 64:1655-1663.

49. Stakleff KD, Von Gruenigen VE: Rodent models for ovarian cancer research. Int J Gynecol Cancer 2003, 13:405-412.

50. Dinulescu DM, Ince TA, Quade BJ, Shafer SA, Crowley D, Jacks T: Role of Kras and Pten in the development of mouse models of endometriosis and endometrioid ovarian cancer. Nat Med 2005, 11:63-70.

51. Kojima T, Oh-eda M, Hattori K, Taniguchi Y, Tamura M, Ochi N, Yamaguchi N: Molecular cloning and expression of megakaryocyte potentiating factor CDNA. J Biol Chem 1995, 270:21984-21990.

52. Hassan R, Kreitman RJ, Pastan I, Willingham MC: Localization of mesothelin in epithelial ovarian cancer. Appl Immunohistochem Mol Morphol 2005, 13:243-247.

53. Ordonez NG: Value of mesothelin immunostaining in the diagnosis of mesothelioma. Mod Pathol 2003, 16:192-197.

\section{doi:10.1186/1757-2215-4-12}

Cite this article as: Yu et al.: The hen model of human ovarian cancer develops anti-mesothelin autoantibodies in response to mesothelin expressing tumors. Journal of Ovarian Research 2011 4:12.

\section{Submit your next manuscript to BioMed Central and take full advantage of:}

- Convenient online submission

- Thorough peer review

- No space constraints or color figure charges

- Immediate publication on acceptance

- Inclusion in PubMed, CAS, Scopus and Google Scholar

- Research which is freely available for redistribution

Submit your manuscript at www.biomedcentral.com/submit
C Biomed Central 